\title{
Silylated bisketenes: Accessible and reactive organic intermediates
}

\author{
Annette D. Allen, Ronghua Liu, Jihai Ma, Michael A. McAllister, \\ Thomas T.Tidwell, Da-chuan Zhao \\ Department of Chemistry, University of Toronto, Toronto, Ontario, \\ Canada M5S $1 \mathrm{Al}$
}

\begin{abstract}
The thermal or photochemical ring opening of bis(trialkylsilyl) substituted cyclobutenediones 13 gives 1,2-bisketenes 14 which are thermodynamically stable relative to 13 . When only one trialkylsilyl substituent is present the cyclobutenedione 13 is moderately more stable, but has a substantial barrier to ring closure, so that the kinetics of ring closure can be readily measured above room temperature. The observed relative stabilities of 13 and 14 are consistent the substituent effects observed on monoketenes, with some additional effects on the cyclobutenediones 13 , and with ab initio calculations on analogues of $\mathbf{1 3}$ and 14. The structures and reactivity of these bis(ketenes) have been studied, including the preparation of tetra(ketenes).
\end{abstract}

The study of ketene chemistry has continued to blossom, including the examination of the effect of substituents on ketene structure and reactivity (1). The extraordinary stabilizing effect of silyl substituents on ketenes has long been known (2), and the origin of this stabilization has been elucidated by ab initio molecular orbital calculations (3). From the MP2/6-31G*//MP2/6-31G* calculated energies of substituted ketenes 1 and alkenes 2, ketene stabilization energies $S E$ were calculated by the isodesmic reaction of eq. 1 , and these are correlated with the group electronegativities $\chi_{\mathrm{BE}}$ (3c) by eq. 2, as illustrated in Fig. $1(3 \mathrm{a}, \mathrm{b})$. Thus ketenes are stabilized relative to alkenes by electropositive substituents, and destabilized by electronegative groups.

$$
\begin{aligned}
& \mathrm{RCH}=\mathrm{C}=\mathrm{O}(1)+\mathrm{CH}_{3} \mathrm{CH}=\mathrm{CH}_{2} \stackrel{S E=\Delta \mathrm{E}}{\longrightarrow} \mathrm{CH}_{3} \mathrm{CH}=\mathrm{C}=\mathrm{O}+\mathrm{RCH}=\mathrm{CH}_{2}(2) \\
& S E(\mathrm{MP2})=-17.0 \chi_{\mathrm{BE}}+46.4 \quad(\mathrm{r}=0.97)
\end{aligned}
$$

These calculations help to elucidate several important aspects of the effects of substituents on ketenes. $\pi$-Acceptor groups such as $\mathrm{BH}_{2}, \mathrm{CH}=\mathrm{O}, \mathrm{NO}$, and $\mathrm{NO}_{2}$ adopt coplanar conformations which permit conjugation between the substituent and the ketene as illustrated in eq. 3 .

This interaction results in stabilization of the ketene, as manifested by positive deviations for these substituents above the correlation line of Fig. $1(3 a, b)$.

The $\pi$-donor substituents cause an unfavorable interaction between the substituent and the excess electron density at $\mathrm{C}_{\beta}$ of the ketene, and consequently the substituents $\mathrm{NH}_{2}$, $\mathrm{OH}, \mathrm{PH}_{2}$, and $\mathrm{SH}$ favor twisted conformations of the substituent in which this unfavorable interaction is reduced, as shown in eq. 4. As discussed elsewhere (3b) there have been suggestions that this preference for the twisted conformation of the substituents is due to an attractive bonding interaction 


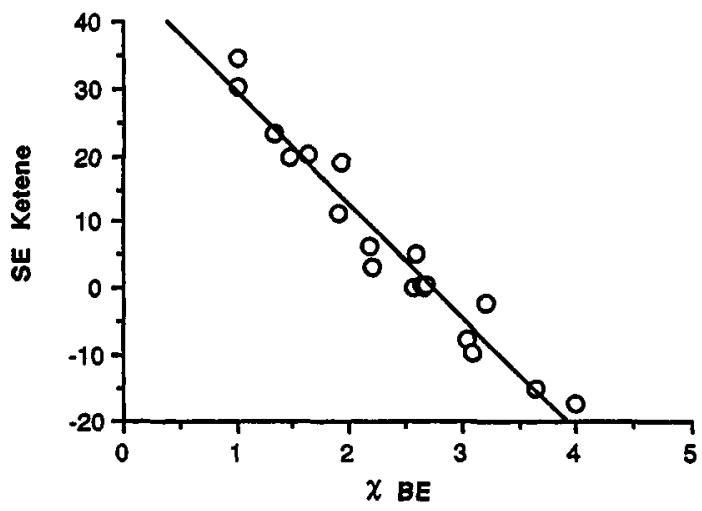

Figure 1.

Correlation of MP2/6-31G*//MP2/6-31G* calculated stabilization energies of bisketenes (eq. 1) with substituent group electronegativities $\chi_{\mathrm{BE}}$.

between the substituent lone pair and the in-plane $p$ orbital of the carbonyl carbon of the ketene. Evidence against this attraction being the major factor causing this conformational preference includes the fact that the anti-lone pair conformation is also more stable than the coplanar arrangement by 40.2 $\mathrm{kJ} / \mathrm{mol}$, and is only $8.4 \mathrm{~kJ} / \mathrm{mol}$ less stable than the syn conformation $(3 \mathrm{a}, \mathrm{b})$.

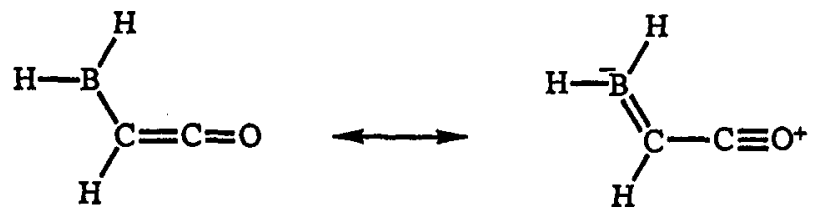<smiles></smiles>

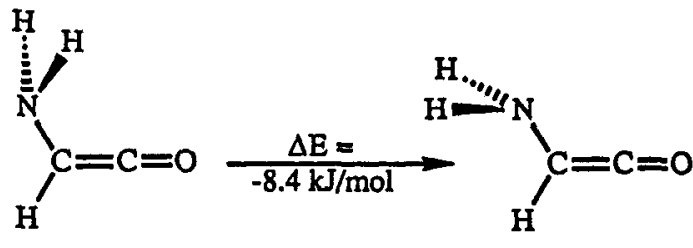

The thermal and photochemical ring opening of cyclobutenediones 3 to form 1,2-bis(ketenes) has long been studied, and evidence has been obtained for the formation of 4-10, as well as others with bis EtO, $\mathrm{ACO}$, and EtS substituents $(4,5)$. Some of these were trapped in cycloaddition reactions or with nucleophiles, and in some cases these were detected spectroscopically by IR or UV at low temperatures, often in matrices or by the use of fast detection techniques $(4,5)$. Comparison of the calculated $31.8 \mathrm{~kJ} / \mathrm{mol}$ stabilizing influence of the $\mathrm{SiH}_{3}$ group on ketene relative to hydrogen (eq. 5) and the fact that the anti conformation of the parent bis(ketene) 8 is calculated to be only $28.9 \mathrm{~kJ} / \mathrm{mol}$ less stable than the corresponding cyclobutenedione 3 (3a) suggested that silylated bis(ketenes) substituted with silyl groups should be observable intermediates.

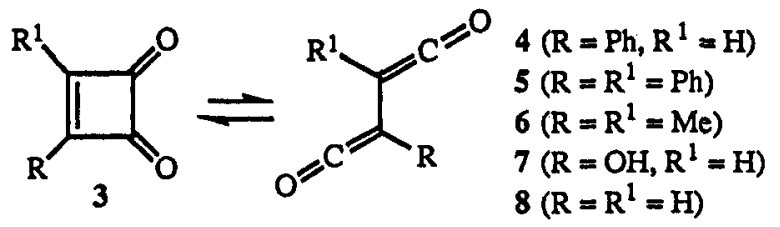<smiles>O=C=c1ccccc1=C=O</smiles><smiles>O=C=C1CCCCC1=C=O</smiles>

$$
\mathrm{SiH}_{3} \mathrm{CH}=\mathrm{C}=\mathrm{O}+\mathrm{CH}_{2}=\mathrm{CH}_{2} \frac{\Delta \mathrm{E}=}{31.8 \mathrm{~J} / \mathrm{mol}}-\mathrm{SiH}_{3} \mathrm{CH}=\mathrm{CH}_{2}+\mathrm{CH}_{2}=\mathrm{C}=\mathrm{O}
$$


To test this prediction silylated cyclobutenediones 13 have been prepared by reaction of trialkylsilyl substituted alkynes 11 with dichloroketene to give the dichlorocyclobutenediones 12 followed by hydrolysis (eq. 6) In confirmation of the prediction when $R$ is also a trialkylsilyl group thermolysis of 13 proceeds to give the more stable bis(ketene) 14 as the only observable product, and these are stable indefinitely in the absence of $\mathrm{O}_{2}, \mathrm{H}_{2} \mathrm{O}$, or other reactive materials (6a).

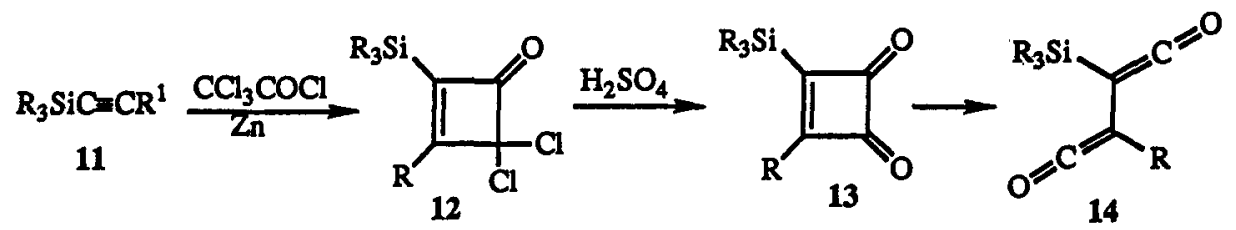

The effect of substituents on the ring opening of cyclobutenediones 3 has been examined by ab initio molecular orbital calculations, and it has been found that while the substituent effects determined for monoketenes by eq. 1 are still manifested in the bisketenes these are significantly attenuated, so that only about half the effect is observed (7a). A substituent effect on the cyclobutenediones is also observed, as these appear to be stabilized by electron donor groups, and destabilized by electron acceptors. This is in accord with the positive charge induced in the ring by its $2 \pi$ electron aromatic character (15). Calculations $(7 \mathrm{a}, \mathrm{b})$, and experimental photoelectron and dipole moment studies (7b) also indicate that the favored structure of the 1,2-bis(ketene) is not a planar form, but rather is a twisted almost perpendicular structure, as indicated by $16 \mathrm{a}$ for the bis( $\left.\mathrm{Me}_{3} \mathrm{Si}\right)$ substituted derivative.

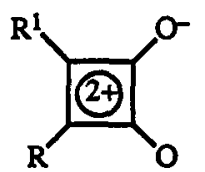

15

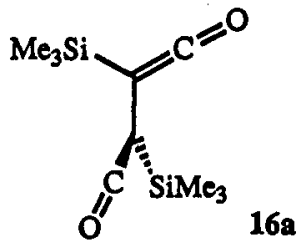

16a

Thus the measured dipole moments of $\mathrm{Me}_{3} \mathrm{SiCH}=\mathrm{C}=\mathrm{O}$ and of the bisketene 16 are $1.8 \pm 0.3$ and $2.7 \pm 0.3$ Debye, respectively (7b). The greater dipole moment of 16 relative to the monoketene excludes an anti coplanar conformation, and while a simple calculation shows that this dipole moment corresponds to a dihedral angle of $80^{\circ}$ the uncertainty in the measurement does not rule out dihedral angles of between $0^{\circ}$ and $120^{\circ}$. The measured photoelectron spectrum of the bisketene 16 below $14 \mathrm{eV}$ (Fig. 2) is accurately reproduced by the synthetic spectrum (Fig. 3), calculated using the HF/6-31G**//HF/6$31 \mathrm{G}^{* *}$ calculated torsional angle of $105^{\circ}$ and the program PESPEC (7c). As is usually found the
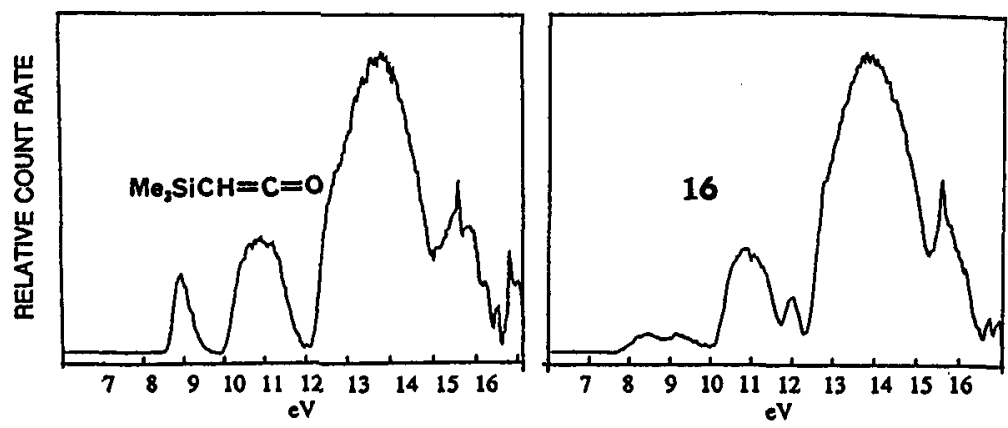

\section{Figure 2.}

Experimental photoelectron spectra of $\mathrm{Me}_{3} \mathrm{SiCH}=\mathrm{C}=\mathrm{O}$ and of bisketene 16. 


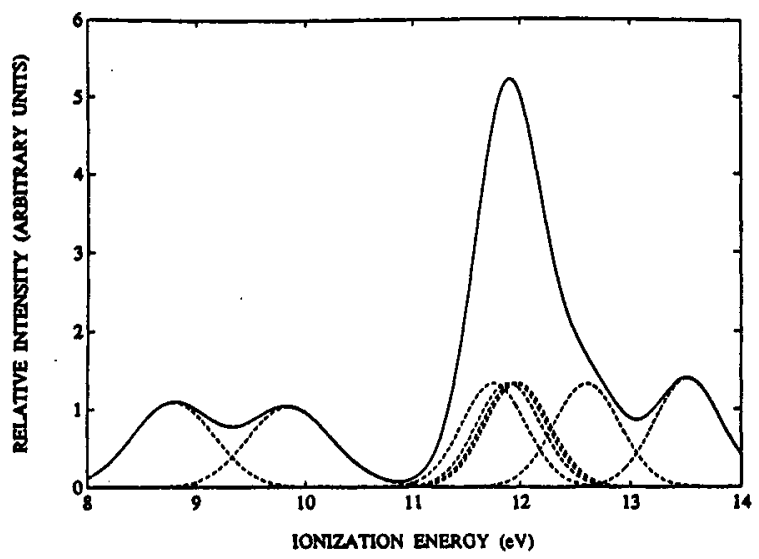

Figure 3.

Synthetic partial ultraviolet photoelectron spectrum of bisketene 16 calculated with PESPEC.

calculated spectrum is displaced by about $0.6 \mathrm{eV}$ to higher energy compared to the experimental spectrum, and when this is taken into account the synthetic spectrum accurately reproduces the broad overlapping bands at 8.4 and $9.1 \mathrm{eV}$ in the experimental spectrum, including the observed HOMO/HOMO-1 splitting of $0.7 \mathrm{eV}$, and the broad features due to 4 or 5 bands centered at $11 \mathrm{eV}$, and provides strong evidence for a twisted conformation with a dihedral angle near $105^{\circ}$. This greater stability of the twisted conformation of bisketenes is not primarily due to steric effects, as even for the unsubstituted derivative 8 the twisted form is calculated to be $10.0 \mathrm{~kJ} / \mathrm{mol}$ more stable (7a). This effect is understandable because of the repulsion between the $\pi$ electrons at $C_{2}$ and $C_{3}$ of the bisketenes and the unfavorable interactions between the two strong ketenyl dipoles in coplanar conformations, and the absence of any favorable conjugation between the dienyl units.

The 1,2-bis(ketenes) are reactive toward a variety of reagents, including $\mathrm{O}_{2}$, water, alcohols, and electrophiles. The reaction of 16 with oxygen leads to the maleic anhydride 17 (eq. 7 ), and a mechanism for this process has been suggested (6a). The reaction with $\mathrm{H}_{2} \mathrm{O}$ has been proposed to involve a ketenyl-substituted carboxylic acid 18, which cyclizes to the observed $E$ and $Z$-anhydrides 19 (eq. 8), whose structures were determined by $\mathrm{X}$-ray crystallography (6a). Confirmation of the intermediacy of 18 in the neutral hydration of 16 is found from the reaction of 16 with aqueous acid, in which an intermediate assigned the structure of 18 was detected by UV, and observed to undergo cyclization to 19 in a step not catalyzed by acid (6d). Photohydration of 16 also led to 18 , which was directly observed by ${ }^{1} \mathrm{H}$ NMR (6d).<smiles>CS(C)(C)C(=C=O)C(=C=O)[As](C)(C)C</smiles>

16<smiles>C[As]C1=C([As])C(=O)CC1=O</smiles>

17
16<smiles>C[As](C)C(=C=O)C([As])C(=O)O</smiles><smiles>C[SiH2]C1C(=O)OC(=O)C1[AlH2]</smiles> 
The reaction of bis(ketenes) 20 with alcohols leads to the mono(ketenyl) esters 21 (eq. 9), which have been characterized spectroscopically, and when $\mathrm{R}=\mathrm{Me}$ or $\mathrm{Ph}$ these are quite stable, and can be purified by VPC $(6 a, b)$. The reactivity of 16 with alcohols has been correlated by the WinsteinGrunwald eq. 10, in which a dependence upon both the solvent ionizing power parameters YOTs and the solvent nucleophilicity parameters NoTs are observed (6a). These parameters are defined for tosylate solvolysis, and are not optimized for nucleophilic additions, but the rather good correlation observed is supportive of a process proceeding through rate-limiting formation of a transition state resembling $22(6 \mathrm{a})$.<smiles>[R]C(=C=O)C(=C=O)C(=O)O</smiles>

20<smiles>[R]C(C)=C(C)C([AsH2])=C=O</smiles>
$\mathrm{HOOR}_{+}^{1}$<smiles>[R]OC(=O)C([R])C(=C=O)[SiH2]C</smiles>

21

$\log k / k_{0}=0.87 N+0.61 Y$

The bis(cyclobutenedione) 23 has also been prepared by a route analogous to that of eq. 6 , and is converted by photolysis to the tetra(ketene) 24 (eq. 11), which has been characterized by IR and NMR (6e). The kinetics of the successive ring closure of 24 first to a bis(ketene) and then to 23 have also been observed (6e). Reaction of 24 with $\mathrm{MeOH}$ leads to a stereoisomeric mixture of tetra(esters) (6e).<smiles>CSc1c(-c2ccc(-c3c(S(C)(C)C)c(=O)c3=O)cc2)c(=O)c1=O</smiles>

23<smiles>C[SiH2]C(=C=O)C(=C=O)c1ccc(C(=C=O)C(=C=O)C(C)C)cc1</smiles>

24

A test of the importance of the positive charge on the cyclobutenedione ring as shown by structure 15 is provided by the effect of aryl substituents on the equilibrium between 25 and 26 , and the rates of conversion of 26 back to 25 (eq. 12). It is found that for an electron-withdrawing group $\mathrm{R}=\mathrm{CH}_{3} \mathrm{CO}$ that the percentage of 26 in equilibrium with 25 is $4 \%$ at $100^{\circ} \mathrm{C}$, as opposed to $1 \%$ for $R=H$, and none observable for $R=\mathrm{MeO}$. Similarly the effect of $R$ on the rates of ring closure of 26 to 25 is in the order $\mathrm{MeO}>\mathrm{H}>\mathrm{CH}_{3} \mathrm{CO}(6 f)$.
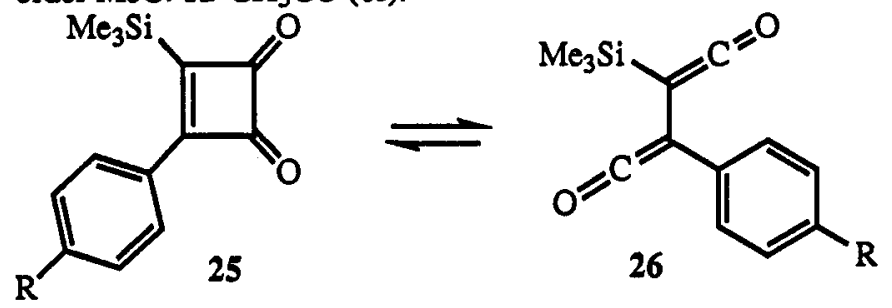

In conclusion the understanding gained from theoretical studies on substituent effects on ketene structures and stabilities $(6 a, b)$ and of the structures and interconversions of cyclobutenediones and bisketenes has permitted the rational synthesis of a variety of new 1,2-bis(ketenes) with a range of 
predictable stabilities. These multi-functional species undergo a variety of interesting and useful reactions which are often not those anticipated on the basis of naive expectations.

ACKNOWLEDGEMENT The contributions of other members of our research group, some of which could not be discussed here, and financial support of the Natural Sciences and Engineering Research Council of Canada, and of the Ontario Centre for Materials Research, are gratefully acknowleged.

\section{REFERENCES}

1. (a) T. Kappe. In Methoden der Organischen Chemie, Vol. 15E, Thieme, Stuttgart (1993). (b) T.T. Tidwell. Ketenes, Wiley-Interscience, New York, in press (1994). (c) T.T. Tidwell. Acc. Chem. Res. 23, 273-279 (1990).

2. (a) L.L. Shchukovskaya, R.I. Pal'chik, and A.N. Lazarev. Dokl. Akad. Nauk SSSR 164, 357-360 (1965). (b) R.A. Ruden. J. Org. Chem. 39, $3607-3608$ (1974). (c) R.L. Danheiser and H. Sard J. Org. Chem. 45, 4810-4812 (1980). (d) Y. Kita, J. Sekihachi, Y. Hayashi, Y. Da, M. Yamamoto, and S. Akai. J. Org. Chem. 55, 1108-1112 (1990). (e) A.D. Allen and T.T. Tidwell. Tetrahedron Lett. 32, 847-850 (1991).

3. (a) L. Gong, M.A. McAllister, and T.T. Tidwell. J. Am. Chem. Soc. 113, $6021-6028$ (1991). (b) M.A. McAllister and T.T. Tidwell. J. Org. Chem. 59, 4506-4515 (1994). (c) R.J. Boyd and S.L. Boyd. J. Am. Chem. Soc. 114, 1652-1655 (1992).

4. (a) F.B. Mallory and J.D. Roberts. J. Am. Chem. Soc. 83, 393-397 (1961). (b) A.T. Blomquist and E.A. Lalancette. J. Am. Chem. Soc. 83, 1387-1391 (1961). (c) N. Obata and T. Takizawa. Bull. Chem. Soc. Jpn. 50, 2017-2020 (1977). (d) O.L. Chapman, C.L. McIntosh, and L.L. Barber. J. Chem. Soc., Chem. Commun. 1162-1163 (1971). (e) R. Hochstrasser and J. Wirz. Angew. Chem., Int. Ed. Engl. 28, 181-183 (1989). (f) R.D. Miller and S. Kirchmeyer. J. Org. Chem. 58, 90-94 (1993). (g) E.V. Dehmlow. Tetrahedron Lett., 1271-1274 (1972). (h) G. Maier and W.A. Jung. Tetrahedron Lett. 21, 3875-3878 (1980). (i) H. Bock, W. Ried, and U. Stein. Chem. Ber. 114, 673-683 (1981).

5. (a) H.A. Staab and J. Ipaktschi. Chem.Ber. 101, $1457-1472$ (1968). (b) D.R. Boate, L.J. Johnson, P.C. Kwong, E. Lee-Ruff, and J.C. Scaiano. J. Am. Chem. Soc. 112, 8858-8863 (1990). (c) T. Mosandl and C. Wentrup. J. Org. Chem. 58, 747-749 (1993). (d) M. Kasai, M. Oda and Y. Kitahara. Chem. Lett. $217-218$ (1978). (e) G. Maier, H.P. Reisenauer, and T.Sayrac. Chem. Ber. 115, 2192 2201 (1982).

6. (a) D. Zhao, A.D. Allen, and T.T. Tidwell. J. Am. Chem. Soc. 115, 10097-10103 (1993). (b) A.D.Allen, W.-Y. Lai, J. Ma, and T.T. Tidwell. J. Am. Chem. Soc. 116, 2625-2626 (1994). (c) A.D.Allen, W.-Y. Lai, R. Ji, J. Ma, and T.T. Tidwell. J. Heteroatom Chem. 6, in press (1994). (d) A.D. Allen, J. Ma, M.A. McAllister and D.-c. Zhao. submitted for publication. (e) R. Liu and T.T. Tidwell, manscript in preparation. (f) R. Liu, unpublished results.

7. (a) M.A. McAllister and T.T.Tidwell. J. Am. Chem. Soc. 116, 7233-7238 (1994). (b) N.H. Werstiuk, J. Ma, M.A. McAllister, T.T. Tidwell, and D.-c. Zhao. J. Chem. Soc., Farad. Trans. in press. (c) N.H. Werstiuk, G. Timmins, J. Ma, and T.A. Wildman. Can. J. Chem. 70, 1971-1977 (1992). 